\section{La argumentación, el orador y su auditorio}

Argumentation, the speaker and his audience
Centro Sur

Social Science Journal Julio - Diciembre Vol 4 No 2

http://centrosureditorial.com/ind ex.php/revista elSSN: 2600-5743 revistacentrosur@gmail.com Recepción: 1 abril 2019 Aprobación 2 julio 2019 Pag 175 - 189

Atribución/ReconocimientoNoComercial-Compartirlgual 4.0 Licencia Pública Internacional CC BY-NC-SA 4.0 https://creativecommons.org/lice nses/by-nc-sa/4.0/legalcode.es

Silvio José Castellanos Herrera ${ }^{1}$

\section{Resumen}

Parte este trabajo, del concepto clásico de argumentación, para desarrollarlo posteriormente en favor de quien debe utilizar las técnicas adecuadas con miras a convencer o persuadir en determinada dirección, a un receptor que debe sumarse a su propuesta. De esta manera tomaremos como base el libro de Perelman referido, en especial el capítulo, 'La argumentación, el orador y su auditorio'. Es entonces claro nuestro objetivo de incrementar con puntos concretos, la habilidad del orador para que su desenvolvimiento ante su variado auditorio -jueces, contraparte, testigos, jurado, etc.- sea óptimo, no solo con las técnicas argumentativas adecuadas a cada situación, sino con un desempeño eficiente de todos los elementos que deben alimentar su discurso. Veremos como todo esto va más allá del manejo de una lógica perfecta en las fundamentaciones de sus tesis; vale decir, una preparación física adecuada, una disposición psicológica firme, un dominio corporal en todas sus facetas, una hegemonía profunda de la esencia de sus planteamientos y un conocimiento previo y cabal del conjunto de personas que desea adherir a su proposición. En este camino, incluiremos interesantes puntos de vista y experiencias, tanto de reconocidos autores, como de quien suscribe estas líneas.

Palabras clave: Argumentación, retórica, auditorio, orador, silogismo

\footnotetext{
1 Ph.D en Derecho. Docente de la Universidad Católica de Cuenca. Extensión "San Pablo de La Troncal Ecuador. ORCID 0000-0001-6633-6998. Email: silvio.castellanos@ucacue.edu.ec.
} 


\section{ABSTRACT}

This work starts from the classic concept of argumentation, to develop it later in favour of those who must use the appropriate techniques with aiming to convincing or persuading in a certain direction a recipient who must join their proposal. In this way we will take as its basis the book of Perelman referred, in particular the chapter, "The argumentation, the speaker and his auditorium". It is then clear our objective of increasing with specific points, the ability of the speaker to make his presentation before his varied auditorium - judges, counterparts, witnesses, jury, etc. - optimal, not only with the appropriate argumentative techniques for each situation, but with an efficient performance of all the elements that must feed his discourse. We will see how all this goes beyond the management of a perfect logic in the foundations of his thesis; that is, adequate physical preparation, a firm psychological disposition, a bodily mastery in all its facets, a deep hegemony of the essence of their approaches and a prior and thorough knowledge of the set of people who wish to adhere to their proposal. In this path, we will include interesting views and experiences, both from renowned authors and from those who subscribe to these lines.

Keywords: Argumentation, rhetoric, auditorium, speaker, syllogism

\section{Introducción}

Creemos necesario, primero que todo, decir sintéticamente que, argumentar es el conjunto de acciones lingüísticas, tendentes a dar razones provenientes del mundo de los hechos, para sostener o refutar un determinado planteamiento (Atienza 2006 p.73) y que el argumentador, que llamaremos en este trabajo 'el orador', es el individuo que sostiene esas razones con la fuerza debida, a objeto de convencer, persuadir o acrecentar la adhesión de un auditorio a las tesis que se presenta a su asentimiento (Perelman 2007 p.29).

En este marco, desarrollaremos un trabajo consistente en comentar y reflexionar, acerca del capítulo 'La argumentación, el orador y su auditorio', contenido en el libro "El imperio retórico - Retórica y argumentación" del autor Chaïm Perelman (2007), con el fin de arribar a conclusiones que pudieran mejorar el performance de los litigantes que necesariamente tienen que desenvolverse oralmente. Pasaremos por analizar los tipos de argumento, dependiendo del contexto en el cual se explanarán, las condiciones y preparación del orador y el público hacia el cual va dirigido el 
discurso, con un particular énfasis en un receptor muy especial que es, 'El Juez', personaje a quien hay que persuadir o convencer.

Aquí ilustraremos cómo debe el profesional del derecho, poner en práctica todos los elementos de la técnica oratoria para apuntalar sus argumentos; resaltando que, si no establece estrategias asociadas a los diferentes tipos de argumentos a exponer oralmente, podría perderse en la controversia. Haremos énfasis en que no es lo mismo alegar por escrito que oralmente; dado que, los argumentos deben ser diferentes cuando se presentan en vivo que cuando se plasman fríamente en papel.

Ahora bien, además de la revisión bibliográfica obligatoria, nuestro aditamento estará presente con el fin de aliñar el texto con los toques personales resultantes de la experiencia, la observación y la asunción de los diferentes roles que nos ha tocado desempeñar.

\section{Materiales y métodos}

Dado que el orador se plantea como finalidad, modificar las convicciones del auditorio para ganar su adhesión sin imponer su voluntad por la fuerza, el prestigio del hablante como elemento influyente es importante, aunque no determinante en el escenario; asimismo la oportunidad de su intervención y la vocería de un grupo o institución de prestigio, son elementos que de alguna forma acondicionan al auditorio para el cambio que se desea en sus espíritus (Perelman 2007 p.31).

Se desprende luego, que es fundamental la personalidad del orador, la forma de mostrarse y la actitud que toma al hablar ya que estos aspectos condicionan la impresión que deja en quien le oye (Bernabé 2007 p.20). Por estas razones y en la misma línea de Aristóteles, Cicerón y Quintiliano, en quienes se apoya Perelman (Alexy 2008 p.157), observamos que modernamente en cuanto a comunicación se refiere, se han propuesto un sinnúmero de técnicas para que el orador cumpla su cometido de manera eficiente, entre las cuales consideramos que vale la pena resaltar las que mostramos en el siguiente gráfico: 


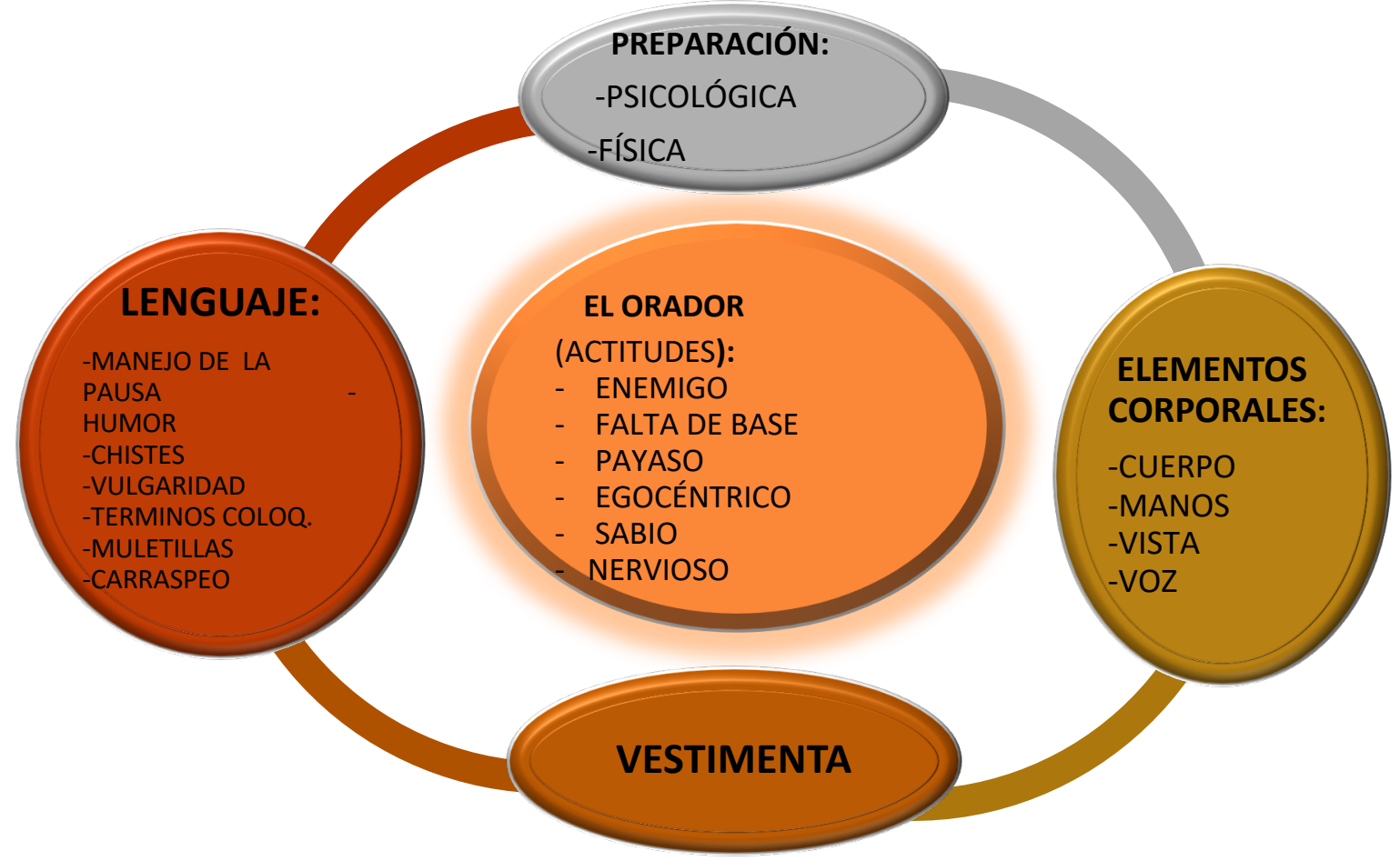

Fuente: Elaboración propia

Sobre las actitudes del orador, es importante que éste no vea a su público como un enemigo; sino más bien, a personas a quienes va a conducir hacia una mejor posición en cuanto a sus conocimientos se refiere. Es decir, si nos vamos a dirigir a un público, no debemos predisponernos pensando en que el mismo es un oponente, puesto que una actitud en ese sentido nos colocaría automáticamente a la defensiva al inicio de nuestra presentación. Ver al público como aliado suaviza nuestra conducta y nuestro espíritu. En cuanto al tema sobre el que vamos a discurrir o a argumentar, nuestra preparación debe ser óptima, conocer a fondo sobre lo que vamos a alegar, recordemos que vamos a persuadir o a convencer, razón por la cual el dominio sobre el tópico a tratar debe ser amplio y profundo. Somos de la opinión de que cuando nos presentemos al auditorio, debe ser con la idea de que quienes nos escuchan son doctores en la materia.

El amplio conocimiento sobre el tema a controvertir, no debe hacernos caer en la tentación de enseñar a los oyentes lo mucho que sabemos, puesto que ellos son el objeto hacia el cual va dirigida nuestra disertación. Una actitud presuntuosa podría tornarse en desventaja al apreciar el público, visos de egocentrismo o arrogancia. Recordemos que, en el ambiente de una audiencia, prevalece la máxima de que 'el 
Juez conoce el derecho' y le corresponde a él dirimir la controversia a través de una sentencia en la que la lógica sea la rectora. Esto se traduce en que el discurso de este último debe convencer en vista de que la decisión beneficiará a una parte y perjudicará a otra (Zerpa 1999 p.191). Este requisito impuesto

Nos referimos entonces a una construcción argumentativa en donde el silogismo tal y como lo diseñó Aristóteles, es lo que marca la pauta, es decir, el Juez debe en primer lugar, llevar a cabo un ejercicio intelectual que deje en claro las premisas a través de la inducción, la deducción, y la teoría de la argumentación, para de esta forma establecer la correcta conexión entre los hechos probados y los preceptos jurídicos aplicables -justificación externa-; en segundo lugar a través del método deductivo arribar a una conclusión que perfectamente se desprenda de las premisas -justificación interna- (Wróblewski 1985 p.57-68); debiendo este andamiaje constituirse en un razonamiento consistente, en el que las premisas al ser verdaderas, generen una conclusión verdadera (Mendoca 1997 p.57).

En líneas generales lo descrito es considerado por la doctrina como 'motivación', es decir, como el factor de razonamiento crítico integrado por el grupo de análisis de hecho y de derecho que constituyen el basamento del decisor (De la Rúa 1991 p.146) y de manera más precisa, el agrupamiento sistemático de razonamientos contentivos de los argumentos de hecho y de derecho presentados por los contrincantes, su revisión en virtud de las probanzas, de las respectivas concordancias legales y el criterio del juez acerca de la naturaleza de la controversia (Cuenca 1980 p.132). En conclusión, el juez no hace más que construir las premisas que utilizará en su quehacer de subsumir los hechos probados en las normas jurídicas aplicables, para llegar a la parte dispositiva. Visto gráficamente, tendríamos: 


\section{SILOGISMO JURÍDICO}

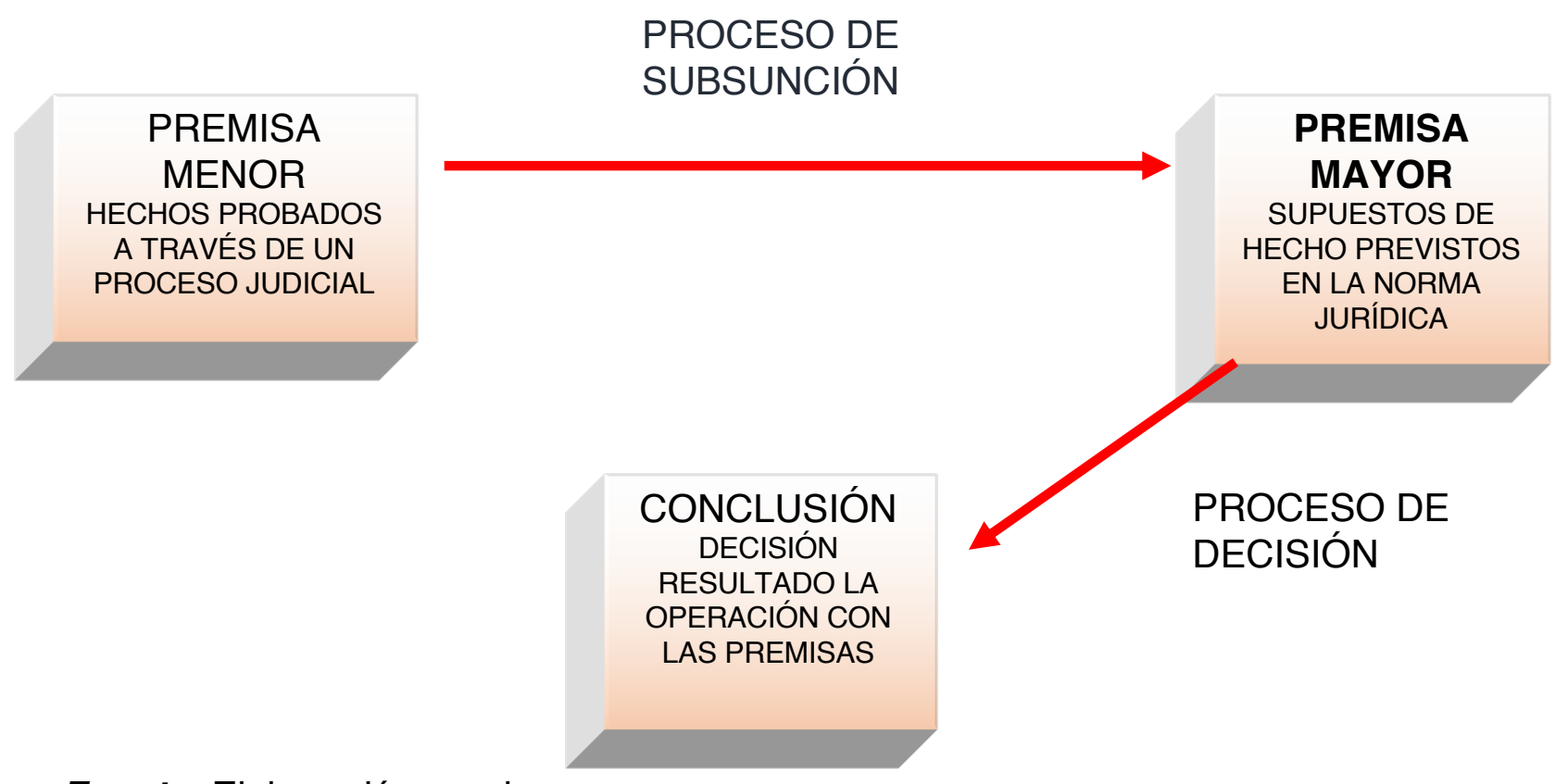

Fuente: Elaboración propia

Esta actividad judicial es imperativa para los jueces, lo cual generalmente, así está establecido, tanto en las constituciones como en los códigos adjetivos existentes de todas las naciones. Como norma procesal es obligatorio para el juez que motive de manera consistente, lógica y coherente a fin de evitar que su sentencia esté signada por el despotismo o la parcialidad, garantizándose así el 'debido proceso'1.

Ahora bien, visto cómo la sentencia contiene en gran medida el discurso de los oradores - partes-, conmover a este decisor pasa por la humildad de hacerle ver que es él quien comanda la escena, pero, debemos impresionarlo sin jactancia con alegatos bien estructurados con un silogismo impecable, recordando siempre que no es lo mismo argüir por escrito que oralmente. Con esto queremos significar, que la fundamentación escrita conlleva estrategias diferentes a la oral, debido a que las técnicas de la oratoria forense implican un desenvolvimiento silogístico diferente al que se necesita para los discursos textuales. Obviamente, el exordio cambia en ambos escenarios. Ante un oyente, este pasa a tener una importancia fundamental que puede signar el resto de la audiencia debido a su efecto persuasivo.

\footnotetext{
${ }^{1}$ Constitución de la República de Ecuador. 2008. Artículo 76, numeral 7, literal 1: "Las resoluciones de los poderes públicos deberán ser motivadas. No habrá motivación si en la resolución no se enuncian las normas o principios jurídicos en que se funda y no se explica la pertinencia de su aplicación a los antecedentes de hecho. Los actos administrativos, resoluciones o fallos que no se encuentren debidamente motivados se considerarán nulos. Las servidoras o servidores responsables serán sancionados."
} 
Pero, tanto el exordio como los otros elementos del discurso -narración, demostración, refutación, conclusión y epílogo (Aristóteles. Retórica 141a-141b) deben ser adornados con una retórica que incluya técnicamente todas las partes del discurso. ¿Esto por qué? Porque el Juez alimentará su sentencia con los argumentos lógicamente estructurados por el orador; he ahí la importancia crucial de que este último conozca profundamente el tema en el que le tocará navegar.

En cuanto a nuestra preparación como orador, se hace indispensable que dispongamos una noche antes, de la tranquilidad necesaria que nos conduzca psicológicamente a una estabilidad emocional, a fin de que dominemos la situación y no sucumbamos como víctima de las circunstancias. La preparación física también juega aquí un papel importantísimo puesto que una postura débil, con cansancio y con respiración agitada, puede hacernos perder la fuerza de los dichos; recordemos que en muchos casos debemos desplazarnos en el escenario, lo cual implica movimientos flexibles, naturales, suaves y con discreción.

El manejo de los elementos corporales es fundamental ante un público que espera ser convencido o persuadido. Esto es, exhibir siempre una imagen erguida, pero sin rigidez, ya que un cuerpo encorvado denota derrota; la gesticulación es crucial, las manos deben moverse con gracia, dibujando o acompasando nuestro discurso sin cruzar los brazos y sin introducir las manos en los bolsillos. En general, los movimientos corporales debemos coordinarlos con las expresiones verbales y los gestos de manera armoniosa, en otras palabras, debe haber una concordancia plena entre el movimiento del cuerpo, la gesticulación y lo que se dice. En esta misma dirección diremos que los gestos groseros, las vulgaridades y las miradas inadecuadas pueden hacernos perder todo lo que hemos logrado hasta un momento determinado.

La mirada es quizás el punto neurálgico del orador. Por supuesto esto dependerá del número de personas que conforma nuestro auditorio. En el caso de que nuestros oyentes sean por ejemplo los integrantes de un jurado, es crucial una mirada eficiente. Esto es, debemos iniciar nuestra exposición mirando de manera segura, tranquila y sin temores, a una persona y cambiar de oyente con cada frase, por ejemplo: 


\section{ORADOR}

\begin{tabular}{c|c|c} 
PASO & CONDUCTA & DISCURSO \\
\hline 1 & $\begin{array}{c}\text { Mira a una persona del } \\
\text { jurado y dice: }\end{array}$ & $\begin{array}{c}\text { Nos hemos reunido hoy aquí para } \\
\text { revisar los hechos que } \\
\text { presumiblemente inculpan a mi } \\
\text { defendido }\end{array}$ \\
\hline 2 & $\begin{array}{c}\text { Deposita la mirada sobre } \\
\text { otra persona del jurado y } \\
\text { dice: }\end{array}$ & $\begin{array}{c}\text { Demostraremos en este día que el } \\
\text { señor josé antonio díaz, no tuvo nada } \\
\text { que ver con los hechos que se le } \\
\text { imputan }\end{array}$ \\
\hline 3 & $\begin{array}{c}\text { Posa la mirada sobre el juez } \\
\text { y dice: }\end{array}$ & $\begin{array}{c}\text { Debido a que con las pruebas que } \\
\text { evacuaremos en este audiencia de } \\
\text { juicio, concluiremos de manera } \\
\text { unánime que él es inocente }\end{array}$ \\
\hline
\end{tabular}

Fuente: Elaboración propia

Esta técnica permitirá una conexión permanente entre el orador y sus oyentes y transmitirá seguridad, estabilidad, convicción y posible verdad de sus planteamientos, además de que lo coloca en dominio de la escena.

De manera encadenamos, desplazamiento, gesticulación, manejo de la mirada y hegemonía, en la tarima, completando con la voz, el quinteto de elementos corporales que nos ubican como expositor, en una posición exitosa. Esta última debe ser pausada, haciendo las inflexiones moderadas en los momentos álgidos y con una modulación que demuestre fonética agradable al oído.

Bajo control del escenario, con conocimiento del tema, con una mirada que esté conectando a todos, con dominio del cuerpo y de la voz, debemos comportarnos de una manera elegante evitando el chiste, la vulgaridad, términos coloquiales, muletillas y el carraspeo. El humor con finura siempre agradará al asistente. La ordinariez caerá mal, así el público sea de baja ralea puesto que él siempre pensará que el expositor es un hombre de altura.

En cuanto a la vestimenta, según nuestra opinión, esta complementa los aspectos corporales y de manejo de la voz. Según sondeos personales producto de nuestra experiencia en el área, una indumentaria inadecuada, generalmente creará una imagen negativa en los asistentes, que puede poner en peligro nuestro objetivo con respecto a ese público. Por eso cuando decimos: 'el hábito no hace al monje', replicamos con certera agudeza: 'pero cómo lo ayuda', resaltando entonces que una imagen dice más que mil palabras. Pudiéramos sobre este particular aseverar, sin temor a equivocarnos que, la vestimenta deberá acoplarse al auditorio o en general 
deberá ser un soporte a la imagen que queremos crear en el público, en virtud de nuestro discurso. No significa lo anterior que una vestimenta inadecuada, de manera determinante hará fracasar el objetivo del orador, sino que nos coloca en desventaja de entrada ante nuestro auditorio. Asumimos que a todos estos aspectos hacía referencia Aristóteles cuando se refería a "...el comportamiento del que habla" (Aristóteles. Retórica).

Dominados los ítems antes comentados, estos se tornarían inútiles si no preparamos como oradores nuestra disertación. Esto es, ¿cuánto tiempo tenemos para hablar?, ¿cuáles puntos van primero y cuáles después?, ¿cuánto tiempo dedicar a la introducción, al desarrollo y a la conclusión?, ¿cuánto debemos hablar de cada punto?, ¿en qué momento hacer preguntas?, ¿en qué momento proponer ejercicios?, ¿cuándo contar una anécdota?, ¿debe el público participar, de qué manera?, y así, programar en el tiempo hasta los ademanes a utilizar. Si no planificamos la presentación corremos el riesgo de ir de un lado para otro sin orden alguno, lo que pondría en peligro la transmisión de la información y por ende el objetivo a lograr que no es más que la persuasión y/o convencimiento de nuestros escuchas.

EL AUDITORIO: Elemento receptor del discurso del orador. El concepto básico en la teoría de Perelman (2007), y en esto se dirige a los abogados, es el del auditorio, vale decir, el conjunto de aquellos a quien quiere persuadir o convencer el orador a través de su argumentación. Enfatiza él que: “... un abogado que alega en un asunto comercial o criminal, político o de derecho común, de derecho privado o de derecho internacional público, y según el género de tribunal que se trata de convencer, no utilizará ni el mismo estilo ni el mismo tipo de argumentos."

Nótese aquí que debiéramos conocer las motivaciones del auditorio, bien sea este un jurado, un parlamento o un conjunto de oyentes que esté o no de acuerdo con su manera de pensar, con el fin de adaptar su discurso a los receptores, concluyéndose así entonces que "La argumentación es por ello una función del auditorio" (Alexy 2008). Apoyamos luego el enfoque de Aristóteles cuando manifiesta que hay que conducir al oyente hacia específica posición emocional, lo que nos induce a manejar algunos conceptos generales sobre psicología, asociados a los diferentes tipos de escuchas y sobre sus estructuras emocionales con el objeto de decir lo que él quiere escuchar (Aristóteles. Retórica 1356ª).

Compartimos con Perelman y por supuesto con Aristóteles, que es muy variable el conjunto de individuos que conforma el auditorio, comenzando por el orador mismo cuando se trata de una deliberación íntima. Sobre este punto en particular acostumbraba Descartes a persuadirse a sí mismo con argumentos convincentes 
antes de exponerlos a los auditores. En general acordamos también con Zenón en que el mejor conocimiento del interlocutor y del objeto del debate, posiciona al orador convenientemente en cuanto a su objetivo. Por esta razón era común también en Sócrates, aplicar la técnica de preguntas y respuestas cuando tenía un auditorio pequeño. Sin embargo, cuando el público está conformado por un conjunto de variados especialistas, asumimos que esta técnica resulta inoficiosa debido a los múltiples enfoques que los presentes pueden aflorar.

Por otra parte, si el orador se dirige a un público especializado, domina con más facilidad las tesis en que puede fundamentar su exposición, mientras que si el orador es un filósofo, su discurso está dirigido a un auditorio universal por lo que soportará su intervención en "hechos, verdades y valores universales que, aún si las tesis invocadas no son objeto de adhesión explícita por todos los miembros del auditorio universal, debe imponerse a todo ser de razón suficientemente ilustrado." (Perelman 2007). Finalmente, dado que el objetivo es persuadir o convencer, somos proclives a pensar igual que San Agustín citado por Perelman (2007 p.33) cuando dice que, realmente un público es motivado cuando en su actuar, luego del discurso, se mueve en la misma dirección que marca el orador; así temerá a lo que se le indujo a temer y se alegrará por las mismas causas que el orador sugirió. Es así como en general, el concepto que se tenga del auditorio determinará la forma de argumentar.

Luego, cuando exponemos ante un público debemos conocer con anticipación qué clase de personas lo integran, ya que esto determinará el nivel del discurso. Igualmente, nuestra preparación para el manejo de las vicisitudes durante el transcurso de nuestra intervención, no debe descuidarse.

Queremos con esto manifestar que siempre habrá interrupciones de alguien que quiere demostrar que sabe más que el exponente, por lo que haremos de este individuo un aliado; asimismo es de esperarse que nos topemos con un enemigo intelectual que tratará de ridiculizar nuestra posición, lo cual manejaremos con mucha sutileza y elegancia para demostrar nuestra amplitud en cuanto a la aceptación de otras ópticas se refiere; también es común encontrar a quien sin tener base suficiente interviene, oportunidad esta que no debemos desaprovechar para ampliar conceptos sin ridiculizar al individuo; la persona que quiere mostrarse como muy conocedor de la materia y que eventualmente quiere un protagonismo a toda costa, no es extraño, debemos manejarlo como colaborador o complemento de nuestro tema; en esta variedad de situaciones nos encontramos con el líder que quiere también tomar el mando de la conferencia, a los antagonistas que quieren aprovechar el escenario para profundizar alguna polémica, al payaso que siempre quiere hacer reír a sus amigos, a la oveja negra de quien todos quieren burlarse, al monopolizador que quiere centrar 
el discurso solo en algún tópico de su interés, y al desinteresado que está en la sala por compromiso, etc.

En fin, el auditorio es rico por las múltiples posturas que asumen sus componentes, pero una actuación ponderada aunada a los aspectos detallados en los párrafos anteriores, nos hará salir airosos en nuestro objetivo de convencer o persuadir.

\section{Resultados}

La técnica y metodologías antes planteadas, nos conducen como consecuencia inequívoca, a la búsqueda de un clímax como lo es convencer y/o persuadir a un decisor específico; ¿pero, cómo?, a través de LA ARGUMENTACIÓN. Ya hemos dicho en palabras de Atienza (2004) que "Argumentar es razonar es una actividad que consiste en dar razones a favor o en contra de una determinada tesis que se trata de sostener o de refutar."; pero ¿con qué objeto?, no podemos reducir la finalidad a la pura adhesión intelectual, sino que generalmente ella busca influenciar para motivar la acción o crear un estado de cosas tendente a un cambio de conducta que se manifieste en el mundo exterior, en un contexto en el que diferenciamos perfectamente la dialéctica como método de la controversia, de la retórica como disciplina del discurso público y de la lógica como técnica de la aplicación de las reglas para conducir el pensamiento (Perelman 2007 p.32-37).

Se desprende entonces lo crucial de la dialéctica en la argumentación como así lo testimoniaron los diálogos socráticos y de otros pensadores que se basaron en ella, teniendo siempre en cuenta el discurso convincente con premisas y argumentos universales aceptables, en principio, por todos los miembros del auditorio.

En este contexto, nos anunciaba Aristóteles (Retórica 1358b 2-7) tres tipos de géneros discursivos a saber, según el rol del auditor: el deliberativo, el judicial y el epidíctico.

En el género deliberativo -sobre el porvenir- el argumento se dirige a aconsejar o desaconsejar y la posición del orador se orienta hacia lo que él considera mejor. En el género judicial el orador dirige su argumento a acusar o defender con el fin de lograr lo justo y en el género epidíctico, el orador trata de lograr la adhesión a su posición basándose en valores y en aspectos subjetivos relativos por ejemplo a lo bello y lo feo, que es lo que al final va a motivar a su auditorio hacia la acción.

Aunque el autor bajo análisis concluye que, si el discurso va dirigido a un auditorio universal, con premisas y argumentos universalizables, entonces será convincente, 
nos inclinamos a pensar que, si los planteamientos quedan en lo general, corremos el riesgo de perder la especificidad que puede enriquecer el argumento cuando conocemos a fondo el auditorio. En otras palabras, la globalidad de la exposición arriesga el objetivo del orador, debido a que los oyentes pueden no experimentar la llegada del discurso a su fibra emocional, perdiéndose así la conexión ideal entre el público y el orador, relación esta expresada por Perelman (2007) a manera de máxima cuando dice: "el único consejo de orden general que una teoría de la argumentación puede dar en este caso, es el de exigir al orador que se adapte a su auditorio."

Por lo expuesto en el párrafo anterior, somos de la opinión de un estudio detallado del auditorio que nos conduzca a la preparación de los argumentos más adecuados. En esa línea nos plegamos a la posición de Atienza cuando analiza a estos efectos, los argumentos desde dos perspectivas: 'el problema' y su 'solución', situándonos en la segunda, la argumentación constituye el hilo conductor que armoniza de manera lógica, sistemática y natural, el arribo desde las premisas a la conclusión, utilizando como método insoslayable, la inferencia (Atienza 2006 p.75).

Ahora bien, como consecuencia, dando por sentado que argumentar es afianzar, con fundamento y pruebas, una conclusión determinada (Weston 1999 p.13), Atienza presenta como enfoques de argumentación las perspectivas deductiva y dialéctica, a través de tres concepciones a saber: la formal, la material y la pragmática (Atienza 2006 p.80-94).

La argumentación desde el punto de vista formal es característica de la lógica deductiva presente en el silogismo sistematizado por Aristóteles, en su "Tratado de Lógica" (Libro Primero, Sección Primera, Capítulo 1), en donde un argumento es un encadenamiento de proposiciones en el que se cumple siempre que, si las premisas son verdaderas, entonces también lo es necesariamente la conclusión, en virtud de la forma de los enunciados que lo componen. En pocas palabras, Aristóteles ve como argumentación deductiva -formal-, al set de proposiciones que constituyen la disciplina de alcanzar la eliminación de los alegatos de los que nos contrarían y de imposibilitar que nuestros propios fundamentos se sometan a semejantes a sus ataques (Nidditch 1980 p.13).

La concepción material, plantea la argumentación de otra manera. Persigue mostrar si existen o no razones para creer en una tesis. Se trata entonces de ver cuál de los conjuntos de premisas envueltas en una confrontación dialéctica resulta mejor fundado y cuál de los dos conjuntos de premisas expone un mejor apoyo a la conclusión respectiva. Asómase aquí entonces el planteamiento presentado por Aristóteles en cuanto a Lógica Dialéctica se refiere. 
Finalmente, en la perspectiva pragmática, la argumentación se nos presenta como una interacción entre dos o más entes o individuos, introduciéndonos entonces en una actividad social. Con esta óptica plantea Atienza que a su vez el enfoque pragmático se subdivide en dos: el primero toma como fundamento a la Retórica, centrando su acción en la idea de persuadir o convencer a un auditorio, en donde la argumentación asume un papel esencialmente estático; y el segundo, aunque dialéctico, propone una interacción dinámica y constante entre un proponente y un oponente.

Los enfoques anteriores en la praxis, son susceptibles de ser enriquecidos. Es así como para casos concretos, existen innumerables clasificaciones. Sin ánimo de ser exhaustivos, nos acogemos a la clasificación de Tarello (1980):

- "A contrario

- A simili ad simile

- A fortiori

- A completudine

- A coherentia

- Psicológico

- Histórico

- Reductio ad adsurdum

- Teleológico

- Económico

- De autoridad

- Sistemático

- Naturalista

- De equidad

- De analogía"

\section{Conclusiones}

En las circunstancias en las que se presenta la trilogía ORADOR-AUDITORIOARGUMENTO, el protagonista o centro de gravedad lo viene a materializar EL ORADOR. Decimos esto porque es él quien, con una buena técnica, buen verbo, figura y dominio de la escena, convence, persuade, estimula e induce una conducta en el auditorio. Logra su pretensión luego, si modifica el estado inicial de pensamiento de sus escuchas en cuanto a un tema en particular y promueve de esta manera, acciones tendientes a poner en práctica la nueva concepción adquirida por ellos, sobre el tópico explanado; y tanto es así que muchos oradores con dominio excelente de su cuerpo, su discurso y del público, han logrado que este último realice las más grandes barbaridades, muestra de lo cual está llena la historia. Cobra vital importancia 
entonces, un dominio profundo del tema a presentar, un prestigio que le preceda a efectos de credibilidad, un manejo corporal que se armonice con sus dichos, una conducta en la tarima que haga fluir su alocución de manera natural y una programación del discurso que no deje detalle alguno al azar.

En relación al público, el conocimiento previo de éste es esencial, recuérdese que el mismo será el objeto de nuestro discurrir como oradores. Por lo tanto, cuando asumamos ese papel, debemos hacer el esfuerzo necesario para aplicar los efectos y métodos adecuados según sea el objeto de nuestro parlamento y el tipo de auditorio. Como abogados, dependiendo del tema, del juez y del jurado debemos ajustar el estilo y los argumentos. Por eso, de manera inequívoca nos plegamos a la línea de Perelman (2007) cuando dice: "El único consejo de orden general que una teoría de la argumentación puede dar en este caso, es el de exigir al orador que se adapte a su auditorio."

En cuanto a nuestra argumentación, dependiendo del tema y del público, debemos componer de manera preconcebida la intervención, tomando en cuenta las orientaciones de Aristóteles en cuanto a si será deliberativo, judicial o epidíctico, así como también la formulación de Atienza en cuanto a si se planteará de manera formal o categórica (Yoris 2009 p.85), material (no deductivo) o pragmática (dialéctica), o si llevaremos a cabo enfoques mixtos, planificando para cada caso los argumentos específicos, tomando como referencia la clasificación propuesta por Torello (1980).

En general, es indiscutible que el objetivo del orador, especialmente en su desenvolvimiento judicial como abogado que debe representar a una de las partes en litigio, es persuadir y/o convencer, en los términos ya explicados. Para el logro de ese objetivo debe conectar de manera planificada, los tres elementos que lo llevarán al éxito: ORATORIA - RETÓRICA - ARGUMENTACIÓN. Si es buen orador pero no tienen lógica sus argumentos, hará el papel de payaso, por más que se adorne con una excelente retórica o quiera manejar eficientemente las falacias Atienza (2006) ${ }^{2}$. De la misma opinión Pereda (1986 p.107 y 297).

En fin, pensamos que las siguientes expresiones ilustran claramente las posibilidades del orador en juicio:

\section{ORATORIA ^ RETÓRICA SIN ARGUMENTACIÓN $=>$ ALTA PROBABILIDAD DE FRACASO}

\footnotetext{
2 "Lo esencial de las falacias es, así pues, ese elemento de engaño, de apariencia, que puede ser intencional o no por parte del que argumenta. Al igual que la ideología no equivale simplemente a error (las ideologías reflejan también en parte la realidad, hablan de la realidad, aunque en una forma distorsionada), los argumentos falaces no son simplemente los malos argumentos, sino los argumentos que por su parecido con los buenos (tienen, pues, algo en común con los buenos argumentos) pueden confundir, engañar a los destinatarios de los mismos e incluso al que los emite; el que construye un discurso ideológico puede no tener ninguna intención de producir engaño (él participa sinceramente de esa visión ideológica -deformada- del mundo), y lo mismo ocurre con el que argumenta falazmente: él mismo puede ser la víctima de su argumento falaz."
} 
ORATORIA ^ ARGUMENTACIÓN SIN RETÓRICA $=>$ MEDIANA PROBABILIDAD DE ÉXITO

\section{RETÓRICA ^ ARGUMENTACIÓN SIN ORATORIA $=>$ MEDIANA PROBABILIDAD DE ÉXITO}

\section{ORATORIA $\wedge$ RETÓRICA ^ ARGUMENTACIÓN $=>$ ALTA PROBABILIDAD DE ÉXITO}

\section{Referencia}

Alexy R. 1997. El concepto y la validez del Derecho. Gedisa, 2da. Edic., tr. Jorge M. Seña. Barcelona.

Alexy R. 2008. Teoría de la argumentación jurídica. Centro de Estudios Políticos y Constitucionales. Madrid.

Aristóteles. Retórica.

Aristóteles. Tratado de Lógica. El Organon.

Atienza M. 2004. Bioética, Derecho y Argumentación. Editorial Temis. Santa Fe de Bogotá.

Atienza M. 2006. El Derecho como argumentación. Editorial Ariel. Barcelona.

España.

Atienza M. 2009. Las razones del derecho. Editorial Ariel. Barcelona.

Bernabé A. 1998. Introducción, traducción y notas de Alberto Bernabé del libro:

Retórica de Aristóteles. Alianza Editorial. Madrid.

Constitución de la República del Ecuador. 2008.

Cuenca H. 1980. Curso de Casación Civil. Universidad Central de Venezuela,

Ediciones de la Biblioteca. Caracas.

De La Rúa F. 1991. Teoría General del Proceso. Editorial Depalma. Buenos Aires.

Mendoca D. 1997. Interpretación y aplicación del derecho. Universidad de Almería.

Nidditch P.H. 1980. El desarrollo de la lógica matemática. Editorial Cátedra.

Madrid.

Pereda. Carlos. 1986. Argumentación y Filosofía. Ediciones UAM. México.

Perelman Ch. 2007. El imperio retórico. Grupo Editorial Norma. Santa Fe de Bogotá.

Tarello, Giovanni. 1980. Trattato di Diritto Civile e Conmerciale Diretto da Cicu Messineo, Milano, Giuffré Editore. Italia.

Weston A. 1999. Las claves de la argumentación. Editorial Ariel, tr. Jorge F. Malem Seña, 5ta. Reimpresión. Barcelona.

Wróblewski J. 1985. Constitución y teoría general de la interpretación jurídica.

Civitas, tr. Arantxa Azurza. Madrid.

Zerpa L. 1999. La motivación de la sentencia. Criterios de la Sala de Casación Civil. Revista de la Facultad de Derecho de la Universidad Católica Andrés Bello, N

53. Caracas 